\title{
Utilization plants in energy and water supply systems of oil and gas enterprises
}

\author{
Igor Dolotovskij, ${ }^{1, *}$, Nadezhda Dolotovskaya ${ }^{1}$, Evgeniy Larin $^{1}$, and Boris Semenov ${ }^{1}$ \\ ${ }^{1}$ Yuri Gagarin State Technical University of Saratov, Saratov, Russian Federation
}

\begin{abstract}
Within the context of energy efficiency and environmental safety, the creation of energy and water supply systems integrated with the units for utilization of combustible waste, low-pressure gases and industrial wastewater are of high priority for oil and gas enterprises. A method for the synthesis of these rational systems and a two-dimensional model for evaluating performance indicators are proposed. We have developed alternative structures based on the block-modular principle of equipment composition formation, which allows structurally parametric integration of energy and utilization modules with technological productions; performed pre-project evaluation of the effectiveness of alternative options for the energy and water supply system with the utilization of low-pressure gases, thermal neutralization of industrial wastewater for methanol recovery plants and designed a multipurpose oil and gas condensate processing enterprise. Integration of utilization, energy and technological installations in energy- and water supply systems allows reducing the consumption of heat and electric energy from external sources by $56-100 \%$, and water consumption by $40-50 \%$. Accordingly, the cost of wastewater reducing - by an average of $76-93 \%$ for oil and gas condensate processing facilities. Almost complete utilization of lowpressure hydrocarbon gases is achieved (the volume of flared emissions is reduced by $90-98 \%$ ).
\end{abstract}

\section{Introduction}

The development and modernization of the energy complex of oil-gas-condensate raw materials (OGCRM) production, transportation, processing and storage enterprises is currently underway in the direction of creating our own sources of electric and thermal energy based on combined cycle plants (CCGT) and renewable resources.

Scientific research in this area is concentrated in the following areas:

- development of structural and parametric solutions for multi-purpose power generation plants, mainly threegeneration, which combine gas turbine, steam turbine and thermo-transformer cycles (the latter is represented by heat pump or refrigeration machine cycles) [1 - 4];

- numerical experiments on the integration of energy supply systems with individual technological and energy facilities [2, 5 - 9];

- development of methods for assessing the thermodynamic, technical-economic, environmental efficiency and reliability of combined power sources such as CCGT-CHP, including power plants of their own needs [10 - 12];

- thermodynamic analysis of cycles and equipment of CCGT [12 - 15].

The obtained scientific and technical results are adapted mainly for the technological topology of oil and gas enterprises (OGE) for the extraction and transportation of OGCRM or for central power plants. They practically do not reflect a comprehensive solution to the problem of creating OGE energy- and water supply systems (EWSS), which use the potential of lowpressure hydrocarbon gases (LPHG) - gas from fields in the final period of operation, associated petroleum gases, gases of condensate stabilization, and technologies gases from processing enterprises. At the same time, there are particular solutions to the problem of the useful and environmentally safe use of LPHG, which are proposed in the form of utilization methods with the development of technological or energy products $[16,17]$ and the constructive implementation of technical solutions in specific equipment $[18,19]$. Among the many proposed methods for utilization of LPHG for practical use on multipurpose OGE's, the following methods are promising: conversion to methanol, used both for the needs of oil and gas production enterprises, and as raw materials for processing; fractionation and liquefaction, followed by processing into technological products or transportation to the consumer; use as a fuel in electric generating plants their own needs of OGE.

To date, various technologies and methods for treating wastewater and minimizing waste are known [19 - 26], the implementation of which in appropriate equipment can reduce water consumption from external sources of both technological productions of OGE's [19,

\footnotetext{
* Corresponding author: dolotowsky@mail.ru
} 
23, 27] and recycled water supply systems [21, 27]. However, to increase energy efficiency OGE's and create resource-saving energy-technological complexes with practically closed utilization cycles, it is necessary to take into account the trends of the following influencing factors: thermobaric parameters and composition of OGCRM; production nomenclature; operating modes of equipment; environmental-climatic conditions; environmental-climatic conditions; technicaleconomic characteristics. Therefore, the aim of this study is to develop rational EWSS of OGE based on multifunctional plants with the utilization of combustible waste, LPHG and industrial wastewater. The blockmodular principle of forming the composition of the equipment of EWSS OGE allows for their structural and parametric integration with technological productions in the dynamics of development throughout the entire life cycle (LC).

A pre-project evaluation of the effectiveness of the developed structural solutions was carried out according to multi-criteria indicators, reflecting, on the one hand, the effectiveness of the OGE as an economic asset, and on the other hand, its effectiveness in implementing priority areas for improvement:

- the transition to resource-saving energy;

- minimizing the consumption of energy and water from external sources;

- increasing environmental safety and reliability of energy- and water supply from own sources.

\section{Methods}

\subsection{Methodological provisions of the synthesis of EWSS}

The development of rational EWSS schemes carried out using the decomposition-search method for the synthesis of complicated energy technology complexes [28]. For the problems under consideration, the elementary decomposition strategy was applied, and for their solutions, the cutoff decomposition strategy. In accordance with the strategy of elementary decomposition of the EWSS synthesis problems, a set of three interconnected subtasks of lower dimension formed:

- A - combined generation of energy resources (ER) electricity, thermal energy and cold in own sources, including using thermal recovery energy resources (RER) OGE;

- B - utilization of LPHG and combustible waste with the production of technological and / or energy products;

- C - utilization wastewater disposal of the technological subsystem (TSS) and energy complex with the production of technical water.

Variable solutions of subtasks A, B, C (synthesis of rational EWSS's) interconnected, and dependent on the connections of the OGE with external systems for the supply of OGE ER and water. Moreover, the parameters of these external relations vary throughout the LC of the OGE.
During synthesis, in accordance with the principles of cutoff decomposition, the upper and lower boundaries of the criteria of efficiency or quality of functioning of EWSS. The decision itself is determined by searching only in a subset of promising solutions.

In the general case, in the synthesis of EWSS, the initial data are the required parameters of the generated ER and water, the fuel potential, the parameters of the RER, LPHG and effluents in the dynamics of the development of OGE throughout the LC. The capacities of the individual EWSS modules, the structural parameters of the equipment and the set of operational parameters of their functioning in the corresponding period LC are determined. It should noting that the development of an optimal EWSS structure requires the creation of a specialized information-analytical system with updated equipment databases [29, 30]. In the database both unified equipment produced in series and promising technical solutions is including.

The principle of EWSS formation shown in Figure 1 in the coordinates of temperature vs. entropy.

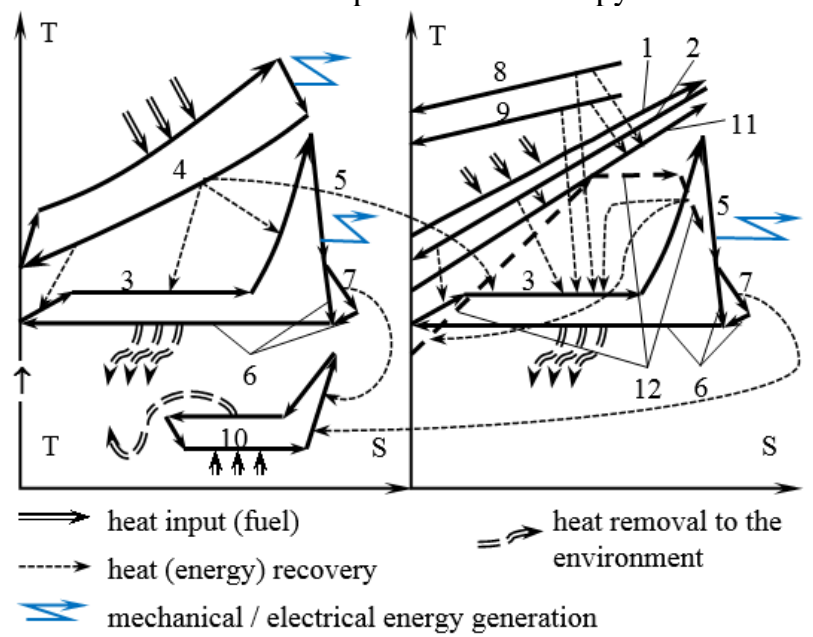

Fig. 1. Processes in multipurpose elements EWSS.

The solution of subtasks A, B and C implementing using the following interrelated processes in the elements of TSS and EWSS:

- generation of electric and thermal energy:

4, 3, 5, 6 - in CCGT of own source (4 - generation of electricity and thermal RER in a gas turbine unit - GTU, 3 - heat recovery of RER GTU in a waste heat boiler WHB, 5 - generation of electricity in a steam turbine unit - STU, 6 - condensation of water vapor in water or aircooled condensers);

8, 9, 3, 5, 6 and / or 1, 2, 3, 5, 6 - in STU of own source $(8,9$ - generation of thermal RER in hightemperature technological equipment TSS, 1, 2 utilization of combustible waste and industrial effluents and generation of thermal RER in thermal neutralizers), 3 - utilization of thermal RER and steam generation in WHB STU or in energy technological units TSS);

11 - utilization of thermal RER in the process equipment of OGE (heat transfer in processes 2-11, 8-11, 9-11);

- cold generation in a vapor compression refrigeration unit (cycle 10) driven by a steam turbine or machine (process 7); 
- utilization of LPHG and combustible waste: 1, 2, 11 and / or 1, 2, 3, 5, 6 - utilization and generation of ER and water; 12, 3, 5, 6 - utilization and generation of technological products and ER;

- wastewater utilization and production of technology water: processes 1,2 and utilization RER according to the processes described above.

\subsection{Performance indicators of EWSS}

The pre-project assessment of the effectiveness of the EWSS as part of the OGE carried out according to the developed two-dimensional model, this including performance and efficiency indicators. Individual indicators by ranking using the hierarchy analysis method [31]. The convolution of the obtained vector indicators into the multi-criteria efficiency index by carried out by analogy with the method for assessing the operational indicators of oil refining enterprises and storage facilities [32].

The set of performance indicators (C) characterizing OGE as a business entity includes vector indicators of the rational option of EWSS in comparison with the basic (most often with the project or existing) option:

$$
\begin{gathered}
\mathbf{C}_{1}=0.540 \overline{T_{1}}-0.297 \bar{T}_{2}-0.163 \bar{T}_{3} ; \\
\mathbf{C}_{2}=-0.5\left(\overline{T_{4}}+\overline{T_{5}}\right) ; \\
\mathbf{C}_{3}=-\left(0.540 \bar{T}_{6}+0.297 \bar{T}_{7}+0.163 \bar{T}_{8}\right) ; \\
\mathbf{C}_{4}=-\left(0.540 \bar{T}_{9}+0.297 \bar{T}_{10}+0.163 \bar{T}_{11}\right),
\end{gathered}
$$

where $\bar{T}_{1}-\bar{T}_{11}$ normalized (relative to the base variant) technical-economic characteristics: $\bar{T}_{1}$ is the value of sold technological and energy products; $\bar{T}_{2}, \bar{T}_{3}$ is the cost of OGCRM, , catalysts and other auxiliary materials; $\bar{T}_{4}, \bar{T}_{5}$ is the costs of ER and water from external sources; $\bar{T}_{6}, \bar{T}_{7}, \bar{T}_{8}$ is the costs for maintenance, repair and depreciation of EWSS and TSS equipment; $\bar{T}_{9}, \bar{T}_{10}, \bar{T}_{11}$ payment to external enterprises for processing and disposal of waste and effluents, payment for emissions and wastewater.

Efficiency indicators $\left(\mathbf{E}_{i}\right)$ make it possible to assess the EWSS from the standpoint of autonomy of ER (independence from external energy supply systems), the degree of use of RER, LPHG, combustible waste and effluents for generating electric energy, from the standpoint environmental safety and the reliability of providing electric energy and water throughout the LC of the OGE.

$$
\mathbf{E}_{1}=0.417 \bar{U}_{1}+0.263 U_{2}+0.160 U_{3}+0.094 \bar{U}_{4}+0.062 U_{5},
$$

where $\bar{U}_{1}$ is the normalized (relative to the base variant) performance for the target products of the OGE; $U_{2}$ is the utilization factor of OGCRM $\left(0<U_{2} \leq 1\right)$; $U_{3}$ is the utilization factor of OGCRM and waste that by used to produce the by-products; $\bar{U}_{4}$ - is the normalized difference between the value of sold products and the cost of OGE and materials; $U_{5}$ is rationalization coefficient of the costs of fuel and ER provided by external systems.

$$
\mathbf{E}_{2}=0.381 \overline{e_{1}}+0.252 \eta_{2}-0.160 \eta_{3}-0.101 \eta_{4}-0.064 \eta_{5}-0.043 \bar{P}
$$

where $\bar{e}_{1}$ is the normalized specific (per unit of target product or recycled OGCRM) consumption of fuel and ER; $\eta_{2}$ is the coefficient of relative deviation (saving) of fuel and ER consumption; $\eta_{3}, \eta_{4}, \eta_{5}$ are rationalization coefficients of power engineering, water consumption and water disposal balances, correspondingly; $\bar{P}$ is the normalized value of the technically feasible potential of using all types of material and energy resources (RER, LPHG, combustible waste, water, sewage).

$$
\mathbf{E}_{3}=0.417 \eta_{e}+0.263 \eta_{E R}+0.160 \eta_{R E R}+0.097 \eta_{e x}+0.062 \bar{B},
$$

where $\eta_{e}$ is energy efficiency coefficient equal to the ratio of the amount of useful and additionally generated energy to the sum of the energy supplied from the external systems and EWSS of OGE; $\eta_{E R}$ is the efficiency coefficient for utilization of all types of ER; $\eta_{\text {RER }}$ is the efficiency coefficient of RER utilization for the generation of heat energy for own needs of the OGE; $\eta_{e x}$ is the exergy efficiency of the OGE [19, 33]; $\bar{B}$ is the normalized value of systemic fuel savings resulting from installing internal generating sources based on the EWSS.

$$
\mathbf{E}_{4}=0.540 \bar{U}_{1}+0.297 \bar{T}_{12}+0.163 \bar{T}_{13},
$$

where $\bar{T}_{12}$ is the cost (normalized value for alternative EWSS options) of creation of reserve electric and thermal capacities, as well as additional costs of external systems for the maintenance of this reserve (additional fuel in start-up and shutdown modes, all types of repairs, equipment replacement) and compensation costs resulting from changes in the balance of electric and thermal power of the system; $\bar{T}_{13}$ is the capital costs for reserve process equipment, depending on technological and design factors, and operating time.

$$
\mathbf{E}_{5}=-\left(0.540 \eta_{3}+0.297 \eta_{4}+0.064 \eta_{5}-0.043 \bar{K}\right),
$$

where $\bar{K}$ is the capital expenditures in the technological equipment of waste disposal installations of industrial effluents and emissions, depending on technological and design factors, and operating time.

\section{Results and Discussion}

The concept of forming SEVO was implemented both for local technological units of OGE [34, 35], and for the enterprise as a whole [36]. A variant of the EWSS 


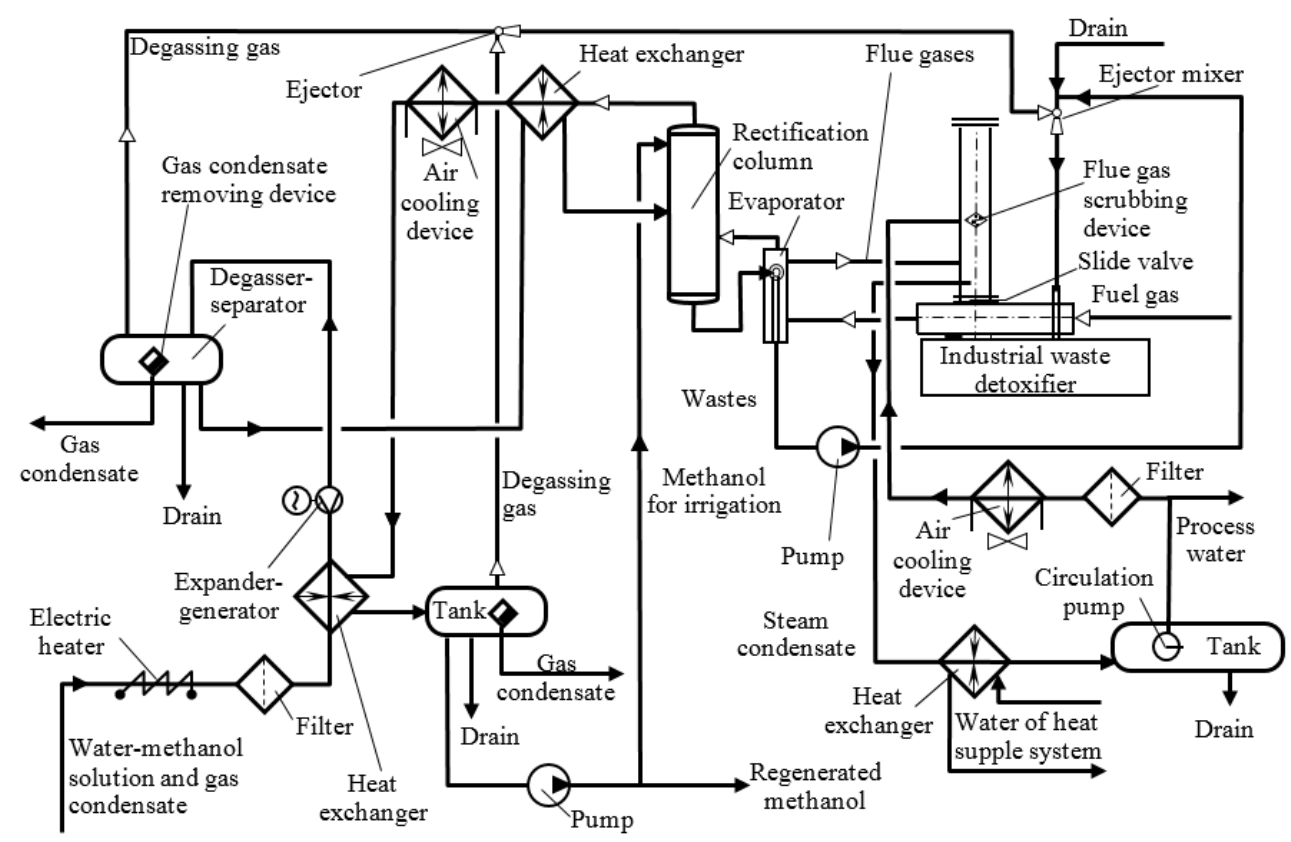

Fig. 2. Functional diagram of methanol regeneration plant.

The analysis of the efficiency of the rational (II) version of the installation is carried out in comparison with the basic (I) version in terms of specific energy consumption $e_{1}$, as well as in terms of the components of the performance set, the relative values of which are shown in Figure 3 [34].

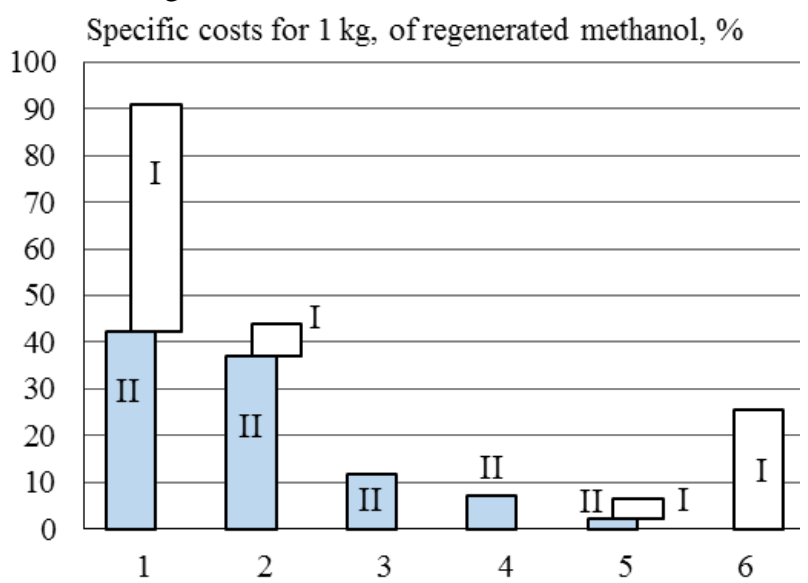

Fig. 3. Operational costs for versions I and II of system. Components of costs: 1 - fuel; 2 - electric power; 3, 4 compensations for gas emissions and effluents within maximum allowable concentration; 5 - water supply; 6 equipment amortization and maintenance.

The maximum integration of energy and technological units by achieved in the installation for producing carbon black (RU 2652237) from gas-phase hydrocarbon feedstocks, including from LPHG [35]. Variants of autonomous EWSS modular types (RU 164323, RU 134993 and RU 118360) with a thermal neutralizer for industrial effluents (RU 2523906, [37]) developing for OGE.
For the EWSS with the generation of electric, thermal energy and cold in the energy block and the thermal neutralization of effluents with the production of industrial water [36], a single module has the following technical characteristics:

- electric power of the power unit equipment (CCGT) 1.9 MW, thermal power 0.7 MW;

- refrigeration capacity of a vapor compression refrigeration unit $0.4 \mathrm{MW}$;

- the volume of utilized industrial effluents is $1.1 \mathrm{~m}^{3} / \mathrm{h}$.

The effectiveness of the EWSS for the OGE expressed in a 56-100\% [34-36] reduction in the consumption of heat and electric energy from external sources of energy supply and in reduction of costs for water consumption from an external source by $40-50 \%$ [27]. Achieved a reduction in the cost of out wastewater by $76-93 \%$ [27]. The volume of flared hydrocarbon gases reduced by $90-98 \%$ [34-37].

\section{Conclusions}

1. Methodological provisions for the synthesis of rational EWSS integrated with utilization and technological units of OGE by developed based on the decomposition-search principle with the choice of decomposition strategies for problems and methods for solving them.

2. A two-dimensional model of indicators proposed for a pre-project assessment of the effectiveness of the EWSS, including vector criteria for technological, energy, economic and environmental effectiveness and efficiency.

3. Original EWSS schemes by developed with combined generation of electricity, heat and cold in 
own sources, including the use of thermal RER, utilization of LPHG and combustible waste with the production of technological and / or energy products, utilization of wastewater of OGE with the production of technical water.

4. An analysis of the effectiveness of the EWSS as part of the OGE by carried out, which showed the feasibility of integrating technological and power plants

\section{Acknowledgements}

The study was funded by the Ministry of Education and Science of Russia (project No. 13.7071.2017 of the basic part of the state task).

\section{References}

1. A.V. Klimenko, V.S. Agababov, A.A. Rogova, P.A. Tideman, Therm. Eng. 3, 166-170 (2015)

2. P. Silva, M. Lamberti, S. Campanari, E. Macchi, A. Bischi, D. Tacchinardi, Energy. 1-10 (2018)

3. N.N. Galashov, S.A. Tsibulskiy, Bull. Tomsk Polytechnic Univ. Geo Assets Eng. 5, 44-55 (2019)

4. A.V. Klimenko, V.S. Agababov, P.N. Borisova, S.N. Petin, A.V. Koryagin, Therm. Eng. 11, 791-798 (2018)

5. V.S. Ezhov, Chem. \& Petr. Eng. 3-4, 220-224 (2018)

6. A.Yu. Izmailov, Ya.P. Lobachevsky, O.V. Shepovalova, Energy Proc. 157, 1445-1455 (2019)

7. A.V. Volkov, A.V. Ryzhenkov, A.G. Parygin, A.V. Naumov, A.A. Druzhinin, A.A. Vikhlyantsev, J. Šoukal, M. Sedlář, M. Komárek, F. Pochylý, P. Rudolf, S. Fialová, Therm. Eng. 11, 799-805 (2018)

8. O.V. Vysokomornaya, V.S. Vysokomorny, P.A. Strizhak, Bull. Tomsk Polytechnic Univ. Geo Assets Eng. 4, 59-65 (2013)

9. Z. Wu, Y. Zhang, Z. He, X. Ma, Y. Sheng, X. Yu, Appl. Therm. Eng. 714-721 (2019)

10. A. Ganjehkaviri, M.N. Mohd Jaafar, P. Ahmadi, H. Barzegaravval, Appl. Therm. Eng. 1-2, 566-578 (2014)

11. T.K. Ibrahim, M.K. Mohammed, O.I. Awad, F. Basrawi, R. Mamat, A.N. Abdalla, M.N. Mohammed, G. Najafi, Renew. \& Sustainability Energy Rev. 90, 835850 (2018)

12. Y. Ust, B. Sahin, M. Cakir, Int. J. of Exergy 1, 39-69 (2016)

13. S. Briola, A. Bischi, R. Gabbrielli, A. Fino, P. Di

Marco, Energy. 179, 709-726 (2019)

14. A.M. Delgado-Torres, Energy Conv. \& Managem. 195, 198-209 (2019)

15. S.W. Moon, H.M. Kwon, T.S. Kim, D.W. Kang, J.L. Sohn, Energy. 160, 625-634 (2018)

16. A.S. Krotov, Y.V. Samokhvalov, D.A. Zhidkov, A.A. Zherdev, A.I. Vlasov, V.O. Yakovlev, V.D. Fedorenko, Chem. \& Petr. Eng. 11-12, 815-820 (2019)

17. P. Iora, C. Invernizzi, T. Rajabloo, P. Bombarda, S.L. Gomez Alaez, P. Silva, Energy Sour. Part A. 21, 3116-3124 (2016)
18. V.M. Pestov, A.V. Yanovskiy, Chem. \& Petr. Eng. 7, 472-475 (2015)

19. V.P. Meshalkin, Resource- and energy-efficient energy supply and waste minimization techniques for refineries: theoretical fundamentals and best practices Chemistry, Moscow-Genoa, (2009)

20. V.V. Burenin, A.N. Sova, A.N. Marinko, Chem. \& Petr. Eng. 9-10, 690-695 (2014)

21. L.A. Nikolaeva, R.Y. Iskhakova, Therm. Eng. 6, 458-463 (2017)

22. V.V. Ul'yanova, N.A. Sobgaida, Chem. \& Petr. Eng. 1, 133-137 (2015)

23. I. Radelyuk, K. Tussupova, M. Persson, K. Zhapargazinova, M. Yelubay, Sustainability. 6, 1618 (2019)

24. V.M. Batenin, V.I. Kovbasyuk, Therm. Eng. 13, 935-937 (2018)

25. P.V. Roslyakov, M.N. Zaichenko, Y.V. Proskurin, Therm. Eng. 9, 644-651 (2017)

26. S.V. Dolgov, S.A. Khaustov, R.B. Tabakaev, Bull. Tomsk Polytechnic Univ. Geo Assets Eng. 9, 49-56 (2016)

27. I.V. Dolotovskii, E.A. Larin, N. V. Dolotovskaya, Water Res. 5, 839-836 (2016)

28. I.V. Dolotovskij, E.A. Larin, N.V. Dolotovskaya, Pure \& Appl. Chem. 10, 1567-1577 (2017).

29. I.V. Dolotovskii, N.V. Dolotovskaya, E.A. Larin, B.A. Semyonov, J. of Physics: Conf. Ser. 1111, 012010 (2018)

30. I. V. Dolotovskii, N. V. Dolotovskaya, E. A. Larin, J. of Physics: Conf. Ser. 1015, 042010 (2018)

31. T. Saaty, L. Thomas, Multicriteria Decision Making - The Analytic Hierarchy Process (RWS Publications, Pittsburg, 1992)

32. A. Tonchev, C. Tonchev, Oil \& Gas J. 10, 56-64 (2005)

33. I.V. Dolotovsky, E.A. Larin, N. V. Dolotovskaya, Procedia Eng. 152, 258-264 (2016)

34. I.V. Dolotovskii, Chem. \& Petr. Eng. 50, 504-507 (2014)

35. I.V. Dolotovskii, Chem. \& Petr. Eng. 54, 322-326 (2018)

36. I.V. Dolotovskij, E.A. Larin, N.V. Dolotovskaja. Therm. Eng. 7, 473-479 (2015)

37. I.V. Dolotovskii, Chem. \& Petr. Eng. 54, 136-139 (2018) 